\title{
Experience and Challenges during Establishment of a Cyclotron and PET-CT facility at National Institute of Nuclear Medicine \& Allied Sciences (NINMAS)
}

\begin{abstract}
Md. Nurul Islam
National institute of Nuclear Medicine \& Allied Sciences (NINMAS)

Correspondence Address: Dr. Md. Nurul Islam, PhD,Professor \& Chief Scientific Officer \& Project Director; Cyclotron and Radiochemistry Division, National Institute of Nuclear Medicine \& Allied Sciences (NINMAS); Bangladesh Atomic Energy Commission; BSMMU Campus; Shahbag; Dhaka; Bangladesh. Email: nurulislam_40@yahoo.com
\end{abstract}

National Institute of Nuclear Medicine and Allied Sciences (NINMAS) is the 'Center of Excellence' and a leading institute amongst all other Nuclear Medicine (NM) facilities in Bangladesh. It is a sister concern of Bangladesh Atomic Energy Commission (BAEC) running under Ministry of Science and Technology (MOST) and located in Bangabandhu Sheikh Mujib Medical university (BSMMU) campus. The Institute started its journey back in 1980 and now it has well equipped Scintigraphy, Nuclear Cardiology, Thyroid, In-Vitro and Ultrasound \& Color Doppler division. Besides it has well established Research \& Development and Medical Physics division that ensures future advancement of NM at the Institute. The seeking and thinking of an establishment of Cyclotron and Positron Emission Tomography-Computed Tomography (PET-CT) facility at the institute initiated inthe year 2003. At that time, Prof. Dr. M. A. Karim, the then Director and now ex-chairman of BAEC, Prof. Dr. Lutfun Nisa, head of scintigraphy division and chief scientific officer Prof. Dr. Kamila Afroj inspired me to plan and submit an annual development project (ADP) on the establishment of Cyclotron and PET-CT facility at NINMAS. Accordingly, the project was submitted and finally approved by MOST on October 09, 2011 as a project titled "Establishment of PET-CT with Cyclotron Facilities". Three latest model PET-CT sytems and one modern medical Cyclotron with Radiochemistry facility were procured for this project.We could successfully install a model of GE Discovery 710 as the first PET-CT scanneron November 2014. This model of GE Discovery 710 used Lutetium based scintillator (LBS) (1) for detection of positron emission and Time of Flight (TOF) (2) technique for data acquisition. A 128 slice CT was included with this PET-CT scanner with a resolution of approximately $0.625 \mathrm{~mm}$ and low radiation exposure as measured with CT Dose Index e.g. CTDI ${ }_{\text {vol }}$-Helical head $17.0 \mathrm{mGy} / 100$ $\mathrm{mAs}$ and $\mathrm{CTDI}_{\mathrm{vol}}-$ Helical body $8.8 \mathrm{mGy} / 100 \mathrm{mAs}$ (1). Second PET-CT scanner was installed at Institute of Nuclear Medicine and Allied Sciences (INMAS), Dhaka Medical College Hospital (DMCH) campus on April 2018 and the third one at NINMAS on January 2019. Both the second and third ones were supplied by Philips Medical Systems and their model was 'Ingenuity TF' having Yttrium doped Lutetium Ortho-silicate (LYSO) crystal detector and modern Time of Flight (TOF) technique for data acquisition (3). A 128 slice CT was included with these PET-CT scanners having a resolution of approximately $0.6 \mathrm{~mm}$ and low radiation exposure as measured with CT Dose Index e.g.CTDI ${ }_{\text {vol }}$ head $11.0 \mathrm{mGy} / 100 \mathrm{mAs}$ and $\mathrm{CTDI}_{\mathrm{vol}}$ - body 5.6 $\mathrm{mGy} / 100 \mathrm{mAs}(3)$.

Cyclotron is a device that accelerates charged atomic or subatomic particles in a constant magnetic field. This type of particle accelerator was very first developed in the early 1930s by two American physicists Ernest Orlando Lawrence and M. Stanley Livingston at the University of California, Berkeley $(4,5)$. On March 2018, main equipment of cyclotron and radiochemistry (Model: Cyclone ${ }^{\circledR} 18 / 9$ from IBAS. A., Belgium) reached NINMAS premises having the ability to accelerate both proton at energy of $18 \mathrm{MeV}$ and deuteron at $9 \mathrm{MeV}$. Enormous hurdles and challenges were faced with the placement of a 100 tons crane during the rigging of the cyclotron in the 
cyclotron bunker as the space was narrow with high voltage electricity cables right in front of the oncology building (Block-F, BSMMU). Breaking down a part of the boundary walls and some already constructed parts of the oncology building and plugging out high voltage electricity connections were way too cumbersome a process. Another big challenge was to slide the 27 tons (approx.) cyclotron in the appropriate place of the cyclotron bunker. Indian experts helped us to get four super strong sliding rollers suitable for the four legs of this heavy machine and place it at the appropriate place. Arranging and solving these undue and uncalculated issues were time consuming and at last on January 07,2019 , it was possible to rig the cyclotron at the designated bunker of oncology basement. Simultaneously the installation of two chillers, four air handling units (AHU), clean room, radiochemistry unit, quality control equipment and radiation safety equipment was completed during this period.

The main objective of this cyclotron establishment is to produce conventional $1{ }^{18} \mathrm{~F},{ }^{11} \mathrm{C},{ }^{13} \mathrm{~N}$ and ${ }^{15} \mathrm{O}$ PET radionuclides. This cyclotron has eight target ports. Primarily four target ports will be chosen for the ${ }^{18} \mathrm{~F}$, one for ${ }^{11} \mathrm{C}$, one for ${ }^{13} \mathrm{~N}$, one for ${ }^{15} \mathrm{O}$ and one for solid target.

Table 1: Some basic uses of the cyclotron produced PET radiopharmaceuticals

\begin{tabular}{lll}
\hline TRACER & IMAGING & CLINICAL USE \\
\hline 18F-FDG & Glucose metabolism & Oncology, neurology \\
18F-FMISO & Hypoxic cell tracer & Oncology, stroke \\
18F-FLT & DNA synthesis & Oncology \\
18F-FCH & Biosynthesis of phospholipids & Oncology (prostate) \\
18F-FDHT & Androgen receptor expression & Oncology (prostate) \\
18F-NaF & Bone Seeking Agent & Oncology \\
18F-FD0PA & Dopaminergic function & Neurology, (Parkinson's) \\
18F-AV1 & Amyloid plaque & Neurology (Alzheimer's) \\
11C-Methionine & Metabolic (Amino acid transport) & Oncology \\
11C-Acetate & Oxidative Metabolism & Cardiology/ oncology \\
11C-Choline & Biosynthesis of phospholipids & Oncology \\
11C-Flumazenil & Benzodiazepine antagonist & Psychiatry, neurology \\
11C-PK11195 & Perif Benzodiazepine antagonist & Neurology, psychiatry \\
11C-PIB & Amyloid plaque & Neurology (Alzheimer's) \\
13N-NH3 & Blood flow & Cardiology \\
15O-O2 & O2 metabolism & Metabolism \\
15O-H20 & Blood flow & Brain activation \\
68Ga-Dotatate & Neuroendocrine tumor & Oncology \\
68Ga-PSMA & Prostate specific membrane & Oncology (prostate) \\
124I-antibody & Tumor & Oncology \\
89Zr-antibody & Tumor & Oncology \\
\hline & &
\end{tabular}

The radiochemistry for ${ }^{18} \mathrm{~F}$ is designed for the radiopharmaceuticals (RPh) of ${ }^{18} \mathrm{~F}$-FDG, ${ }^{18} \mathrm{~F}$-FLT, ${ }^{18} \mathrm{~F}$-FMISO and ${ }^{18} \mathrm{~F}-\mathrm{NaF}(6-10)$. On the other hand, radiochemistry for ${ }^{11} \mathrm{C}$ is designed for the ${ }^{11} \mathrm{C}$-Methionine, ${ }^{11} \mathrm{C}$-Acetate and ${ }^{11} \mathrm{C}$ Choline (11-14) and radiochemistry for ${ }^{13} \mathrm{~N}$ is only for ${ }^{13} \mathrm{~N}_{-} \mathrm{NH}_{3}(15)$. The target for ${ }^{15} \mathrm{O}$ is not included in this project right now but kept in hand for future use.

Solid target in this cyclotron is included for the research \& development and also for advanced tumor imaging in oncology. In recent years, there has been increased interest in nonconventional positron emitters as $89 \mathrm{Zr}$. Since the introduction of the long-lived positron emitter $89 \mathrm{Zr}$ as a residual radionuclide for immuno-PET, procedures have been developed for large-scale production of $89 \mathrm{Zr}$ and its stable coupling to monoclonal antibodies (mAbs) $(16,17)$. It is expected in the future that PET imaging with $89 \mathrm{Zr}$-based tracers will constantly progress, and more promising $89 \mathrm{Zr}$-based tracers should be into clinical use. To diagnose malignant tumors with ${ }^{68} \mathrm{Ga}$ using PET-CT, global demand for positron emitters like $68 \mathrm{Ge} / 68 \mathrm{Ga}$ generators have increased but low number of manufacturing sites are making it hard to meet the demands. So,a cyclotron-based production of ${ }^{68} \mathrm{Ga}$ via the nuclear reaction $68 \mathrm{Zn}(\mathrm{p}, \mathrm{n}){ }^{68 \mathrm{Ga}}$ (from the stable isotope $68 \mathrm{Zn}$ ) will provide an opportunity to ensure patient care with ${ }^{68} \mathrm{Ga}$ radiopharmaceuticals $(18,19)$. Thus alternative production method for ${ }^{68} \mathrm{Ga}$ using solid targets is also possible.

Table 2: Production reaction and characteristics of some conventional PET isotopes

\begin{tabular}{llll}
\hline Radionuclide & Half-life & \multicolumn{2}{l}{$\beta+$ decay* Production } \\
\hline Oxygen-15 & $2.0 \mathrm{~min}$ & $100 \%$ & ${ }^{14} \mathrm{~N}(\mathrm{~d}, \mathrm{n}) 150$ \\
Nitrogen-13 & $10.0 \mathrm{~min}$ & $100 \%$ & $160(\mathrm{p}, \alpha) 13 \mathrm{~N}$ \\
Carbon-11 & $20.4 \mathrm{~min}$ & $100 \%$ & ${ }^{14} \mathrm{~N}(\mathrm{p}, \alpha) 11 \mathrm{C}$ \\
Fluorine-18 & $109.6 \mathrm{~min}$ & $98 \%$ & ${ }^{18} \mathrm{O}(\mathrm{p}, \mathrm{n}) 18 \mathrm{~F}$ \\
\hline
\end{tabular}

Table 3: Production reaction and characteristics of some other PET isotopes from solid targets

\begin{tabular}{|c|c|c|c|c|}
\hline \multicolumn{5}{|c|}{ Other PET isotopes - Solid target } \\
\hline Radionuclide & Half-life $\mathrm{Nu}$ & Nuclear reaction $+\mathrm{d}$ & ay* & Other emissions \\
\hline Copper-64 & 13 hour & 64Ni(p,n)64Cu & $18 \%$ &,$- \gamma(578 \mathrm{keV})$ \\
\hline Yttrium-86 & 14.7 hour & ar $86 \operatorname{Sr}(\mathrm{p}, n) 86 \mathrm{Y}$ & $34 \%$ & $\gamma(1075 \mathrm{keV})$ \\
\hline Zirconium-89 & 3.3 day & $89 \mathrm{Y}(\mathrm{p}, \mathrm{n}) 89 \mathrm{Zr}$ & $23 \%$ & $\gamma(909 \mathrm{keV})$ \\
\hline Iodine-124 & 4.2 day & $124 \mathrm{Te}(\mathrm{p}, \mathrm{n}) 124 \mathrm{I}$ & $23 \%$ & $\gamma(603,1691 \mathrm{keV})$ \\
\hline Gallium-68 & $68 \mathrm{~min}$ & 68Zn(p,n)68Ga & $90 \%$ & $\gamma(1075 \mathrm{keV})$ \\
\hline $\begin{array}{l}\text { GENERATORS: } \\
\text { Gallium- } 68\end{array}$ & $68 \mathrm{~min}$ & $\begin{array}{l}* * 68 \mathrm{Ge}---68 \mathrm{Ga} \\
\text { generator }\end{array}$ & $90 \%$ & $\gamma(1075 \mathrm{keV}) \gamma$ \\
\hline
\end{tabular}




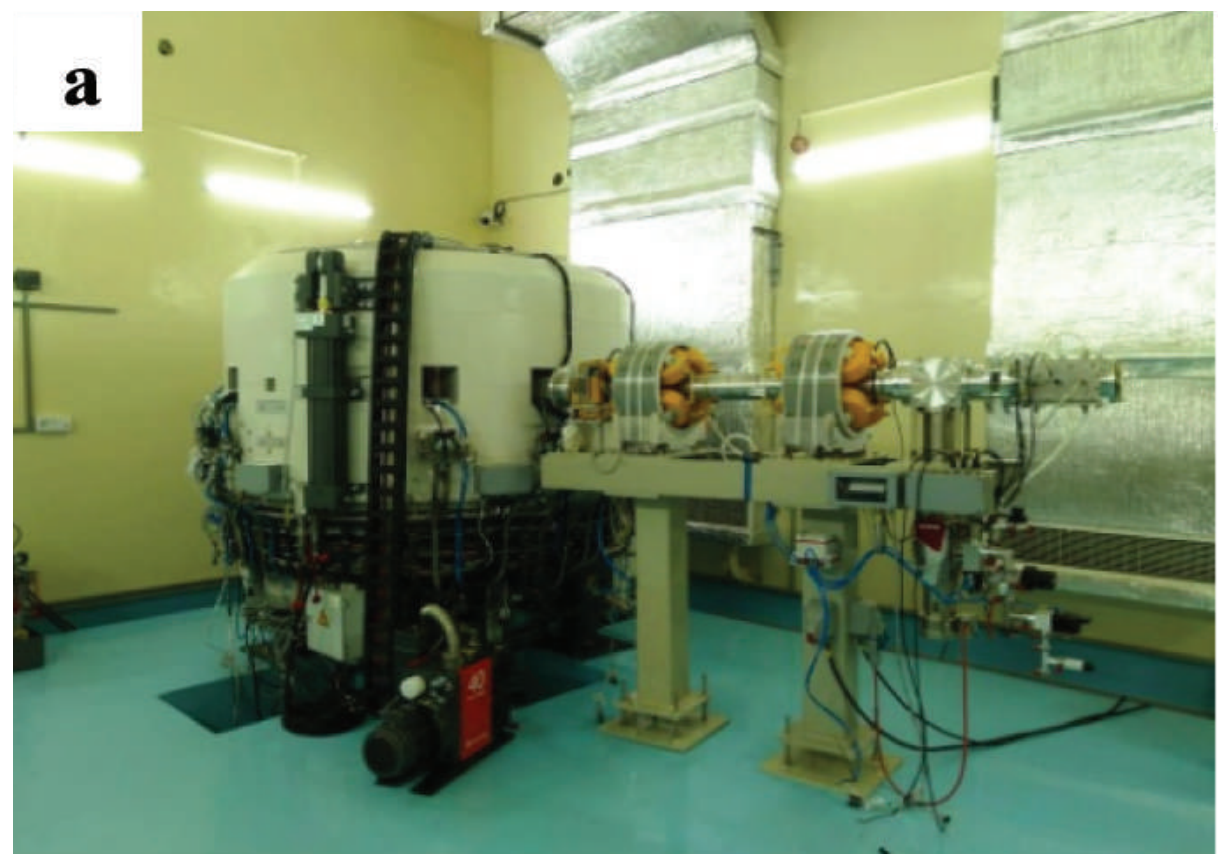

Figure 1: a) Current view of the installed cyclotron at the basement section of oncology building, BSMMU.

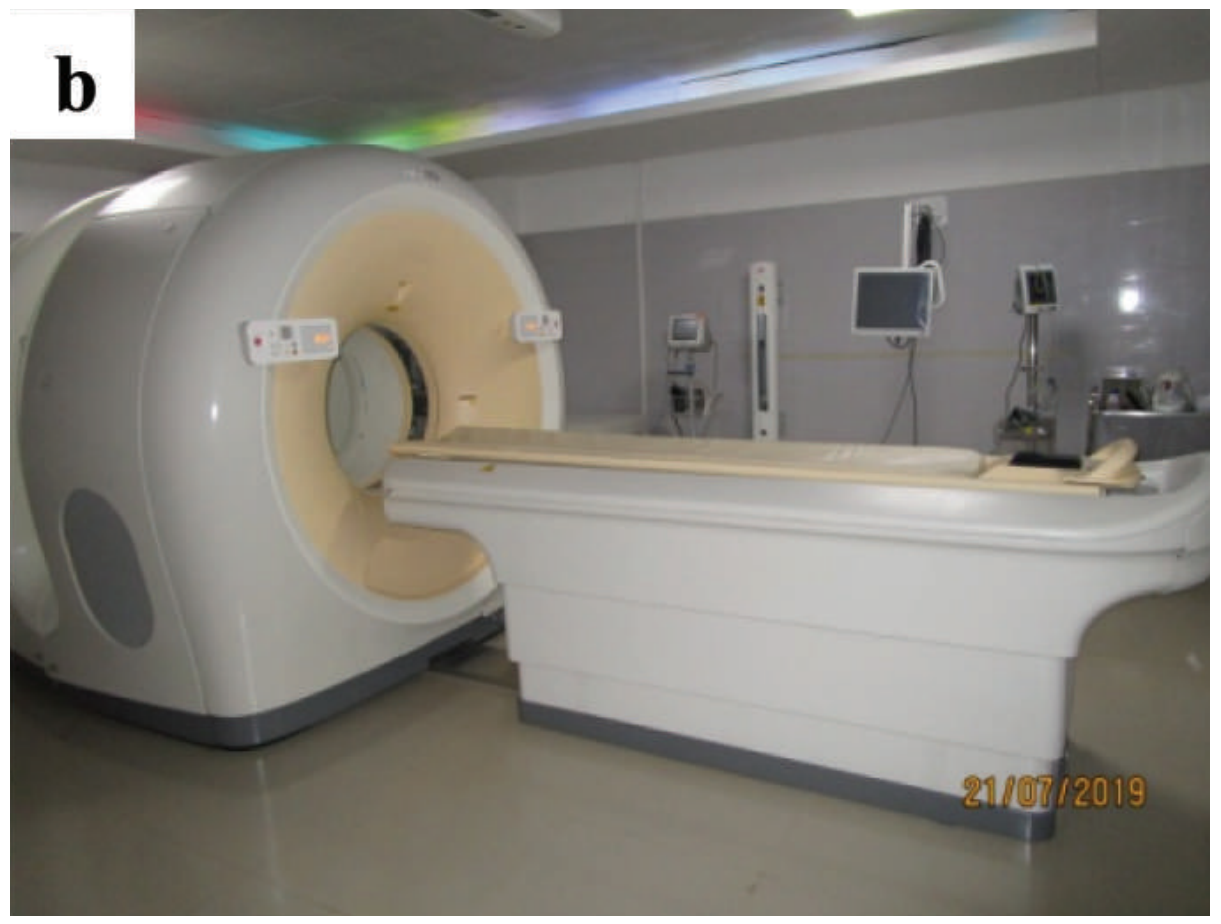

Figure 1: b) Philips Ingenuity TF PET-CT located at the 2nd floor of same building.

The Cyclotron facility at NINMAS is finally established as a project and renamed as "Establishment of Positron Emission Tomography-Computed Tomography (PET-CT) with Cyclotron facilities" and aimed to develop modern services and innovative research in NM with two major agendas a) diagnostic and therapeutic service to patients and b) Physical and biomedical research. Vibrant research activities are a demand of time in the era of precision medicine where NM focuses on theranostics and diagnostics using the state of the art technologies. Cyclotron produced radio-pharmaceuticals are very efficient for molecular imaging and targeted therapy. This project created the possibility of oncologic research in animals and humans ensuring maximum use of the cyclotron 
produced $\mathrm{RPh}$. The scientists of NINMAS have long been working to address these issues with international experts of these fields. It is highly recommended to provide the opportunity for a successive project for the clinical trials of the applications of different $\mathrm{RPh}$ in biomedical fields which would help create a research environment for the multidisciplinary team of physicians, scientists and engineers as well as trained technologists. Development of manpower, research opportunities and patient services will definitely earn more wages and cut down the costs of cancer management in near future. So, the establishment of cyclotron and PET-CT facility will rapidly reduce our dependence on other suppliers and efficiently alleviate patient's burden of disease. It is highly recommended to provide an opportunity for a future project in order to approach for the applications of the cyclotron and radiochemistry of new $\mathrm{RPh}$ to clinical trials.

\section{REFERENCES}

1. GE Healthcare. http://www.gehealthcare.com. Accessed 3 July 2019. General Electric (GE) Healthcare 'Discovery PET/CT 710' Data Sheet; DOC1023430 rev 4.

2. Cherry SR, Sorenson JA, Phelps ME. Physics in nuclear medicine e-Book. Elsevier Health Sciences; 2012 Feb 14. 327-328

3. Source: Philips 'Ingenuity TF' PET/CT specifications, Printed in The Netherlands; 452296266701 JUL 2011, http://www.philips.com/healthcare

4. Lawrence EO. The evolution of the cyclotron. Nobel Lecture. 1951. http://www2.lbl.gov/Science-Articles/Archive/early-years.html), www2.lbl.gov, Retrieved 2018-04-06.

5. Ernest Lawrence - Biographical. NobelPrize.org. Nobel Media AB 2021. Thu. 28 Jan 2019.

$<$ https://www.nobelprize.org/prizes/physics/1939/lawrence/biographical/

6. Pacák J., Točík Z., Černý M.,et. al. "Synthesis of 2-Deoxy-2-fluoro-D-glucose". Journal of the Chemical Society D: Chemical Communications. 1969 (2): 77

7. Fowler JS, Ido T. Initial and subsequent approach for the synthesis of 18FDG. InSeminars in nuclear medicine 2002 Jan 1 (Vol. 32, No. 1, pp. 6-12). WB Saunders.

8. Wagner M, Seitz U, Buck A, Neumaier B, Schultheiß S, Bangerter M, Bommer M, Leithäuser F, Wawra E, Munzert G, Reske SN. 3'-[18F] fluoro-3'-deoxythymidine ([18F]-FLT) as positron emission tomography tracer for imaging proliferation in a murine B-Cell lymphoma model and in the human disease. Cancer research. 2003 May 15;63(10):2681-7.

9. Rajendran JG, Mankoff DA, O'Sullivan F, Peterson LM, Schwartz DL, Conrad EU, Spence AM, Muzi M, Farwell DG, Krohn KA. Hypoxia and glucose metabolism in malignant tumors: evaluation by $[18 \mathrm{~F}]$ fluoromisonidazole and [18F] fluorodeoxyglucose positron emission tomography imaging. Clinical cancer research. 2004 Apr 1;10(7):2245-52.

10. Blau MO, Nagler WI, Bender MA. Fluorine-18: a new isotope for bone scanning. J. Nuclear Med.. 1962 Jul 1;3.

11. Harris SM, Davis JC, Snyder SE, Butch ER, Vāvere AL, Kocak M, Shulkin BL. Evaluation of the biodistribution of $11 \mathrm{C}$-methionine in children and young adults. Journal of Nuclear Medicine. 2013 Nov 1;54(11):1902-8.

12. Le Bars D, Malleval M, Bonnefoi F, Tourvieille C. Simple synthesis of [1-11C] acetate. Journal of Labelled Compounds and Radiopharmaceuticals: The Official Journal of the International Isotope Society. 2006 Mar 15;49(3):263-7.

13. W.B. Saunders., Physics in Nuclear Medicine, "appendix C - Decay Characteristics of Some Medically Important Radionuclides" 2012-04-12, (Fourth Edition), 449-475. ISBN 9781416051985

14. Schliebs R, Arendt T. The cholinergic system in aging and neuronal degeneration. Behavioural brain research. 2011 Aug 10;221(2):555-63.

15. Massimo Castellani, Cristina Canzi, Virgilio Longari, Rosaria Giordano, DavideSoligo, Alessandro Colombo, Simone Palatresi, Marco Carletto, Paolo Rebulla and Paolo Gerundini, et. al. "13N-NH3 PET: The assessment of myocardial perfusion in patients with AMI and stem cell therapy", Journal of Nuclear Medicine, May 2007, 48 (supplement 2) 2P

16. Meijs WE, Herscheid JD, Haisma HJ, Wijbrandts R, van Langevelde F, Van Leuffen PJ, Mooy R, Pinedo HM. Production of highly pure no-carrier added $89 \mathrm{Zr}$ for the labelling of antibodies with a positron emitter. Applied radiation and isotopes. 1994 Dec 1;45(12):1143-7.

17. Verel I, Visser GW, Boellaard R, Stigter-van Walsum M, Snow GB, Van Dongen GA. 89Zr immuno-PET: comprehensive procedures for the production of $89 \mathrm{Zr}$-labeled monoclonal antibodies. Journal of nuclear medicine. 2003 Aug 1;44(8):1271-81.

18. Mai Lin, Gregory J, Waligorsky, Carlos Gonz冈alezLepera et al., Production of Curie quantities of $68 \mathrm{Ga}$ with medical cyclotron via $68 \mathrm{Zn}(\mathrm{p}, \mathrm{n}) 68 \mathrm{Ga}$ reaction, Journal of Applied Radiation and Isotopes, March 2018,133:1-3

19. Lin M, Ta R, Day A, Moin C, Le D, Ravizzini G. Validating Cyclotron-Produced 68Ga as an Alternative Source for Compounding Radiopharmaceutical Kits. Journal of Nuclear Medicine. 2020 May 1;61(supplement 1):466 